\title{
Una fuerte indignación que se convirtió en movimiento: Ayotzinapa
}

Moisés Garduño García*

doi: http://dx.doi.org/10.32870/espiral.v23i66.5306.g4933

El libro aquí reseñado es un texto con una refinada documentación basada en fuentes periodísticas, bibliográficas y testimoniales. En él, los autores exponen con una mirada crítica el impacto nacional e internacional de la desaparición de los cuarenta y tres estudiantes de la Escuela Normal Raúl Isidro Burgos de Ayotzinapa, Guerrero, ocurrida el 26 de septiembre de 2014.

El texto se divide en una introducción, ocho capítulos y una recapitulación. Cada uno de los capítulos ofrece datos ordenados sobre los hechos y las diferentes formas en las que estos han sido narrados tanto desde el poder como desde el contrapoder. La recapitulación problematiza algunas características del movimiento desde algunas resonancias teóricas y, aunque carece de una sección de bibliografía, se debe insistir en que las fuentes con las que se arman las discusiones son excepcionales. Casi todas ellas son fuentes primarias, actuales y provenientes de diversos ángulos críticos. Para el análisis de un movimiento como este, es fundamental tener información producida en el terreno y distanciarse del discurso oficial y lineal, donde el libro recupera las fuentes necesarias y se convierte en una fuente al mismo tiempo.

Carlos Alonso Reynoso y Jorge Alonso (20I5). Una fuerte indignación que se convirtió en movimiento: Ayotzinapa. Guadalajara: Universidad de Guadalajara. 
El texto posee una redacción impecable. Adquiere una fuerte narrativa cuyo eje conductor es la indignación. Dignifica las voces de los participantes de los movimientos a los que alude. Expone claramente que la sociedad mexicana se encuentra entre la violencia perpetrada por el Estado y la proveniente de los grupos criminales. Además, arroja datos que evidencian factores como la pobreza, la marginación, la corrupción y el racismo. Conecta la indignación surgida por el asesinato de Juan Francisco Sicilia Ortega, hijo del poeta Javier Sicilia, con la indignación de los padres de los cuarenta y tres normalistas desaparecidos. Deduce que en ambos casos los jóvenes son las víctimas. A partir de ello, los autores retoman las acciones llevadas a cabo por los padres como resonancia entre un movimiento y otro. En ambos casos, explican, el crimen organizado participa. En ambos casos surge un movimiento pacífico de resistencia. En ambos casos el Ejecutivo tiene que responder, tiene la obligación de aclarar las cuentas. Y en ambos casos fracasa.

El texto enfatiza el papel de los zapatistas en este contexto de indignación. Habla del valioso acercamiento entre este y otros movimientos sociales, y de la solidaridad colectiva que se genera al compartir sus experiencias. Se toca el dilema que implicó para el zapatismo cargar con la agenda del Movimiento por la Paz y la forma en la que esto se va resolviendo con los padres de los cuarenta y tres normalistas a través de la palabra. También se estudia la forma en la que el zapatismo cuestionó con preguntas sólidas la versión oficial de los hechos, la famosa verdad histórica, al grado de ponerla en tela de juicio y rechazarla totalmente. Se expone la forma en que el zapatismo pensó críticamente el problema de Ayotzinapa no como algo meramente local, o nacional, sino como algo sintomático y sistemático de alcance mundial, como un problema de arriba y del capitalismo.

El tema que se aborda en el libro es actual, pero los autores no son inmediatistas. Echan luz sobre el eslogan "Estoy 
hasta la madre", que resonó desde 1968 y que resuena al tiempo de escribir estas líneas. Mencionan que las personas indignadas aluden a 1968 porque fue un año donde explotó un movimiento cuyas víctimas también fueron jóvenes estudiantes y que produjo también un movimiento de padres. Recuerdan que los padres del 68 también reclamaron castigo a los culpables de Tlatelolco, tal como Sicilia lo hizo con su caravana, y tal como los padres de los cuarenta y tres normalistas lo hacen ahora. Con esto, el texto articula la memoria histórica mexicana y la contextualiza con la narrativa "estoy hasta la madre", que renace en un ambiente de fragmentación de los cárteles de droga, su poder, sus conexiones con el Estado, su necropolitica y su papel disuasivo frente a las movilizaciones de la sociedad.

También, el documento aborda puntualmente cada paso que han dado los padres de los normalistas para clamar justicia. Ofrece nombres de periodistas y académicos comprometidos con la causa y la forma en la que el movimiento de Ayotzinapa se conectó con otros en el mundo. El texto describe puntualmente la forma en la que México estuvo en los titulares de los periódicos del mundo, pero también en las asambleas de sus movimientos sociales. Se enfatiza sobre la resistencia contra el discurso oficial y contra las prácticas de corrupción muy conocidas entre los de arriba. Se documentan las múltiples ocasiones en las que el Gobierno intentó comprar a los padres, a los medios, a las mismas escuelas normalistas (cuando les aumentó presupuesto en el ejercicio presupuestal 2015), a la opinión pública. También se documenta la ineptitud del Gobierno. El "iya supérenlo!", el "ya me cansé". A su vez, se documenta también la actitud de la gente: "yo también ya me cansé [del Gobierno]".

El texto en su conjunto explica las formas en las que la tribu yaqui, los zapatistas, los feministas, los movimientos por los derechos humanos, los estudiantes y otros sectores marginados por el Estado se ven reflejados en los sucesos 
de Ayotzinapa. A raíz de esto, el texto aporta reflexiones puntuales para pensar cómo, a un año de esta tragedia, la sociedad mexicana y sus repertorios de movilización están concebidos como una acción glocal, pacífica y antisistémica que prevé seguir clamando justicia en los próximos años.

En resumen, se trata de un texto con un fuerte sustento teórico y documental. Muy necesario y puntual para el contexto donde ha sido publicado. Ayotzinapa de 2014 se relaciona inmediatamente con el Tlatelolco de 1968. Las generaciones nuevas lo piensan así cada vez más. Pero es verdad que de nada sirve la indignación si no se le canaliza en organización, y el libro apuesta a esto justamente. Dice que, en resonancia con otros movimientos en México y el mundo, Ayotzinapa muestra algunas zonas de contacto con la aparición de voceros, marchas, acampadas, la demanda de derechos humanos, la visibilidad internacional, la lucha por la dignidad y la resistencia tanto por las vías institucionales como por las no institucionales. Además, también se muestra la resistencia en lo cotidiano con la esperanza de que se alcance algo extraordinario. La utopía es parte del movimiento y esa utopía se resiste a aceptar la ideología de la estructura estatal.

Una crítica al documento es la carencia de una sección dedicada al movimiento \#YoSoy132, pues a lo largo del libro sólo hay algunas notas que le destacan por momentos. El punto para justificar esta crítica radica en que entre el Movimiento por la Paz de Sicilia y la tragedia de Ayotzinapa el movimiento \#YoSoy132 es un buen eslabón que aporta continuidad al reclamo de justicia que siempre criticó la candidatura de Enrique Peña Nieto y su conexión con Televisa. No obstante, se sabe que uno de los autores ha trabajado a este movimiento de jóvenes en trabajos anteriores con una metodología similar a la que aporta al libro en cuestión. ${ }^{1}$ 
Finalmente, se debe decir que este texto es fundamental para los interesados en destacar lo que ocurre en el México social. Se rescatan la violencia como contexto y los espacios públicos como campos de batalla. Se enfatizan el recrudecimiento de la violencia epistémica y la forma en la que la pobreza aumenta. Se documenta que el desempleo es constante, perturbador, y que la justicia se evapora. Más evidente aún, el texto deja claro que el Estado ha atacado al corazón del esquema de educación popular involucrado con la lucha social en las zonas rurales de México. En la escuela normal de Ayotzinapa se formó gente como Lucio Cabañas y como Genaro Vázquez, dos de los líderes sociales más influyentes de los años sesenta. Además, siguiendo a Adrián Flores (2014), "los normalistas son el primer frente contra el narco en Guerrero", con lo cual se puede decir que llevan cerca de ochenta años en resistencia contra los actores de poder legales e ilegales, ambos ilegítimos y rechazados por la sociedad de la zona.

Para concluir, se utilizan estas las líneas finales para referir a Julio César Mondragón, quien ha sido un símbolo fuerte de la indignación mexicana. Se le desolló el rostro tal como los españoles lo hicieron con los indígenas durante la Conquista. Paradójicamente, su rostro cubrió la campaña de indignación en las calles y en las redes sociales. Su muerte se trató sin duda de un mensaje de disuasión, pero Julio César Mondragón se convirtió y fue convertido, no obstante, en signo de indignación y en un mártir de la causa, respectivamente. Se convirtió en el Jaled Said mexicano. En aquella persona que hizo ver a los narcos como nuestros terroristas, aquel que hizo reflejarnos en un espejo como indignados, aquel que provocó que se llenaran plazas enteras y se escribieran textos como el que aquí se ha presentado. 
Bibliografía

Alonso, J. (2013). "Cómo escapar de la cárcel de lo electoral: el movimiento \#YoSoyl 32”. Desacatos, (42), I7-40. Flores, A. (23 de octubre de 20I4). "5 claves para comprender la masacre de Ayotzinapa". Rebelión. Recuperado de: http://www.rebelion.org/noticia.php?id=191 I57 